\title{
Intracellular Calcium Levels Do Not Change during Contact-mediated Collapse of Chick DRG Growth Cone Structure
}

\author{
Jonathan K. Ivins, ${ }^{1}$ Jonathan A. Raper, ${ }^{2}$ and Randall N. Pittman' \\ Departments of 'Pharmacology and ${ }^{2}$ Anatomy, University of Pennsylvania School of Medicine, Philadelphia, Pennsylvania \\ 19104
}

\begin{abstract}
When the growth cone of a chick dorsal root ganglion (DRG) neurite contacts the neurite of a chick retinal ganglion cell in vitro, the growth cone typically responds by withdrawing its lamellipodia and filopodia and collapsing. We have used the fluorescent calcium indicator dye fura-2 and digital imaging microscopy to measure calcium levels within DRG growth cones and to determine whether changes in calcium levels are responsible for the collapse of growth cone morphology when a DRG growth cone contacts a retinal ganglion cell neurite. Calcium levels within DRG growth cones were stable during neurite outgrowth. Calcium was typically distributed homogeneously throughout the growth cone, though occasionally gradients of free calcium were present. When calcium gradients were observed, calcium levels appeared higher in the active veil regions than in the central core region. Calcium levels in DRG growth cones appeared to remain stable during the period of contact-mediated growth cone collapse. Low concentrations of the calcium ionophore ionomycin increased calcium levels two- to threefold without having any observable morphological effects on DRG growth cones. Likewise, depolarization with $15 \mathrm{~mm} \mathrm{KCl}$ caused a transient two- to threefold increase in calcium levels without having any observable morphological effect. These results suggest that changes in calcium levels are not responsible for contact-mediated collapse of growth cone structure.
\end{abstract}

A growth cone collapsing activity has been solubilized from embryonic chick brain (Raper and Kapfhammer, 1990). Application of this material to cultures of DRG neurons caused growth cones to collapse but had no effect on calcium levels within the growth cones. The crude growth cone collapsing activity was not blocked by the presence of cobalt, nickel, lanthanum, nifedipine, or reduced-calcium medium, suggesting that transmembrane calcium fluxes were not required for growth cone collapse. These results suggest that the morphological changes associated with the collapse of growth cone structure can be independent of changes in growth cone calcium levels, and that second messengers other than calcium are likely to be involved in the regulation of many growth cone behaviors.

\footnotetext{
Received Sept. 24, 1990; revised Dec. 26, 1990; accepted Jan. 4, 1991.

We wish to thank Drs. Stan Kater and Peter Guthrie for help with pilot studies of the soluble growth cone collapsing activity and for their comments on the manuscript. This work was supported by NIH Grant NS 22663 to R.N.P. J.A.R. and R.N.P. are scholars of the McKnight Foundation.

Correspondence should be addressed to Jonathan K. Ivins, Division of Biology, Beckman Institute 139-74, California Institute of Technology, Pasadena, CA 91125. Copyright (C) 1991 Society for Neuroscience $0270-6474 / 91 / 111597-12 \$ 03.00 / 0$
}

During the development of the nervous system, a variety of different factors may alter growth cone dynamics and, therefore, affect growth cone pathfinding, target recognition, and ultimately synaptogenesis. Many factors such as soluble or substrate-bound growth factors (Letourneau, 1978; Gundersen and Barrett, 1980) and components of the extracellular matrix such as fibronectin and laminin (reviewed by Sanes, 1989) provide permissive environments that allow or promote growth cone motility and neurite elongation. Work performed primarily in invertebrates has suggested that the cell surfaces of both neuronal and nonneuronal (Bastiani et al., 1984; Caudy and Bentley, 1986; Kuwada, 1986) cells may guide growth cone navigation. Recent evidence has suggested, however, that negative or repulsive factors may play equally important roles in growth cone guidance in vitro and perhaps also in vivo (reviewed by Patterson, 1988).

When the growth cones of chick sympathetic or sensory neurons contact the neurites of other peripheral neurons in vitro, they typically cross the neurites without any delay (Kapfhammer and Raper, 1987). However, when these growth cones come into contact with the neurites of chick retinal ganglion neurons, they typically undergo a rapid but reversible collapse of growth cone structure. Likewise, the growth cones of chick retinal neurites often collapse when they encounter the neurites of neurons from the PNS. These data suggest the existence of two "labels," one central and the other peripheral, present on the surface of neurons that growth cones are able to recognize and distinguish.

Additional labels may also exist. Nasal retinal growth cones will readily cross either nasal retinal axons or temporal retinal axons. However, temporal retinal growth cones will collapse on contact with nasal retinal axons (Raper and Grunewald, 1990). A similar phenomenon of contact-mediated growth cone collapse occurs between growth cones of cultured sympathetic neurons from the neonatal rat superior cervical ganglion (Ivins and Pittman, 1989).

Bonhoeffer and coworkers have shown that membranes from the posterior tectum of the embryonic chick brain contain a growth cone collapsing activity that is specific for temporal retinal growth cones and has no apparent effect on nasal retinal growth cones (Cox et al., 1990). Keynes and colleagues have isolated a peanut lectin binding fraction from the posterior half of somites of chick embryos and have shown that this material is also capable of causing growth cone collapse (Davies et al., 1990). Raper and Kapfhammer (1990) have also described the partial enrichment of a growth cone collapsing activity from embryonic day 10 (E10) chick brain.

Schwab and Caroni (1988) have reported that a component 
of CNS myelin associated with the cell surface of oligodendrocytes is able to inhibit spreading by $3 \mathrm{~T} 3$ fibroblasts and is a nonpermissive substrate for neurite outgrowth. Time-lapse video microscopy has suggested that the inhibitory effect on neurite outgrowth is an active process (Fawcett et al., 1989): growth cones collapse and retract when they encounter oligodendrocytes in culture.

We are interested in the mechanisms by which contact between growth cones and specific cell surfaces causes such rapid and dramatic changes in growth cone morphology and motility. Several such mechanisms can be envisioned. Because neurites are under tension (Bray, 1979; Joshi et al., 1985; Dennerll et al., 1988, 1989; Condic and Bentley, 1989), a sudden loss of adhesion between the growth cone and the growth substrate might be expected to cause growth cone collapse and retraction (Letourneau, 1987). Similarly, uncoupling of the growth cone cytoskeleton from its sites of attachment to the plasma membrane might cause growth cone collapse. Depolymerization of microfilament and/or microtubule networks within the growth cone might also cause a collapse of growth cone structure. Less direct mechanisms can also be imagined. For instance, because actin polymerization is an ATP-dependent process, neurite outgrowth and growth cone motility might be blocked by a metabolic inhibitor that causes a depletion of the available ATP pools, paralyzing the motile machinery and eventually leading to a collapse of growth cone structure.

Work performed primarily with invertebrate growth cones has suggested that the various signals that regulate growth cone motility are integrated within the growth cone at the level of calcium ion concentration (Kater et al., 1988). Specifically, agents that inhibit growth cone motility, such as changes in membrane voltage (Cohan et al., 1987), the neurotransmitter 5-HT, and calcium ionophores (Mattson and Kater, 1987; Kater et al., 1988), all inhibit growth cone motility by causing large changes in intracellular calcium levels within the growth cone. Many of the potential mechanisms of growth cone collapse described above might either be dependent upon calcium levels or use calcium ions as a second messenger in a cascade of events.

To begin to address the question of the mechanism of contactmediated growth cone collapse, we have used the fluorescent calcium indicator dye fura- 2 and low-light-level digital imaging fluorescence microscopy to determine if changes in intracellular calcium levels occur in growth cones of chick dorsal root ganglion (DRG) neurons as they undergo contact-mediated collapse of structure upon contact with the neurites of chick temporal retina ganglion neurons.

\section{Materials and Methods}

Cell culture. Temporal retinas were dissected from the eyes of embryonic day 6 (E6) chicks and plated as explant cultures on laminin $(40 \mu \mathrm{g} / \mathrm{ml})$ coated glass coverslips (described below) in complete $\mathrm{F} 12$ medium, which contains $5 \%$ fetal calf serum, $5 \%$ chick serum, glutamine ( $2 \mathrm{~mm}$ ), penicillin $(100 \mathrm{U} / \mathrm{ml})$, streptomycin $(100 \mu \mathrm{g} / \mathrm{ml})$, and $7 \mathrm{~S} \mathrm{NGF}(50 \mathrm{ng} /$ $\mathrm{ml}$; prepared from the saliva of male $\mathrm{BALB} / \mathrm{c}$ mice according to Burton et al., 1978), and cultured in a humidified $5 \% \mathrm{CO}_{2}$ atmosphere at $37^{\circ} \mathrm{C}$. Twelve to eighteen hours after plating the retinal explants, dorsal root ganglia were dissected from the lumbosacral region of E7 chicks and placed in coculture with the retinal explants. Cultures were used for calcium measurements when the DRG explants were between approximately 18 and $28 \mathrm{hr}$ old.

Tissue culture dishes were prepared by drilling a $1-\mathrm{cm}$ hole in the bottom of 35-mm tissue culture dishes. Sulphuric acid-washed and silanizcd (Chang et al., 1987) glass coverslips ( $25 \mathrm{~cm}$; \#1, Fisher) were then sealed onto the bottom of the culture dishes with molten paraffin wax. Dishes were sterilized by ultraviolet irradiation. The coverslip portion of the dish was coated with laminin $(40 \mu \mathrm{g} / \mathrm{ml}$ in Hank's buffered salt solution) for $1 \mathrm{hr}$ at $37^{\circ} \mathrm{C}$ immediately prior to plating the neuronal explants.

Video microscopy. For video imaging, the serum-containing culture medium was replaced with serum-free F12 medium. Serum-free F12 medium was prepared from individual components according to the Gibco formulation with the following exceptions: phenol red was omitted, sodium bicarbonate was replaced with an equimolar amount of sodium chloride, and the medium was buffered to $\mathrm{pH} 7.4$ with $20 \mathrm{~mm}$ HEPES. This medium was further supplemented with BSA $(100 \mu \mathrm{g} / \mathrm{ml})$, insulin $(5 \mu \mathrm{g} / \mathrm{ml})$, transferrin $(10 \mu \mathrm{g} / \mathrm{ml})$, selenium $(30 \mathrm{~nm})$, penicillin $(100 \mathrm{U} / \mathrm{ml})$, streptomycin $(100 \mu \mathrm{g} / \mathrm{ml})$, glutamine $(2 \mathrm{mM})$, and $7 \mathrm{~S}$ NGF $(50 \mathrm{ng} / \mathrm{ml})$. Low-Ca ${ }^{2+} \mathrm{F} 12$ was prepared in the same manner except that the $300 \mu \mathrm{M} \mathrm{Ca}{ }^{2+}$ normally in F12 medium was omitted. Fura-2 estimates of the free $\mathrm{Ca}^{2+}$ in this medium indicated that $\mathrm{Ca}^{2+}$ was less than $3 \mu \mathrm{M}$.

The cultures were placed on the stage of an inverted microscope (Diaphot, Nikon) and maintained at $37 \pm 0.2^{\circ} \mathrm{C}$ in $5 \mathrm{ml}$ of medium with a Leiden tissue culture chamber (Medical Systems, Inc.). When observation times of more than $1 \mathrm{hr}$ were required, the culture was overlaid with light mineral oil (Sigma) to prevent evaporation. The microscope was equipped with $40 \times$ and $100 \times$ oil-immersion planapochromat objectives (NA, 1.3) and a 100-W tungsten light source filtered at $546 \mathrm{~nm}$. 'Time-lapse video microscopy was performed using a newvicon camera (Dage MTI, model 65) attached to the side port of the microscope. The camera output was directed to an Image1/AT digital image processing system (Universal Imaging, Inc), where it was corrected for background inhomogeneity and then further contrast enhanced. The resultant images were stored on videotape using a Panasonic AG-6050 time-lapse videotape recorder. Images were printed from the videotapes using a Mitsubishi CP100U video image printer.

Calcium measurements. All calcium measurements were made using a Nikon Diaphot inverted microscope equipped with a $100-\mathrm{W}$ HBO mercury light source and a $40 \times$ quartz oil-immersion planapochromat objective (NA, 1.3; Nikon). To preserve growth cone integrity and to prevent unnecessary photobleaching of the calcium indicator dye (Becker and Fay, 1987), a quartz UV-grade neutral-density filter (optical density, 2.0) was placed in the excitation light path. The fura-2 filter set consisted of two exciter filters, $340 \pm 6.5 \mathrm{~nm}$ and $380 \pm 5.5 \mathrm{~nm}$, a 400 $\mathrm{nm}$ dichroic mirror, and a 510-nm long-pass barrier filter. All filters were from Omega Optical, Inc. Free calcium concentrations were calculated using the equation of Grynkiewicz et al. (1985): $\mathrm{Ca}^{2+}=K_{d}$. $F_{o} / F_{s} \cdot\left[\left(R-R_{\min }\right) /\left(R_{\text {urax }}-R\right)\right] . R_{\text {mini }}$ was determined by measuring the fluorescence intensity of a solution of $5 \mu \mathrm{M}$ fura-2-free acid (Molecular Probes) in a high-potassium Ringer's solution (Thayer et al., 1988) containing $10 \mathrm{~mm}$ EGTA in the absence of added calcium, "sandwiched" between two glass coverslips. Glass chromatography beads ( 75 $\mu \mathrm{m}$ diameter) were used as spacers. $R_{\max }$ was similarly determined using a solution of $5 \mu \mathrm{M}$ fura-2-free acid containing $10 \mathrm{~mm} \mathrm{CaCl}$ in the absence of EGTA. For our microscope, $R_{\min }=0.12, R_{\max }=3.3$, and $F_{o} / F_{s}=10$. The $K_{d}$ of fura-2 for calcium was assumed to be $224 \mathrm{~nm}$ (Grynkiewicz et al., 1985). $R$ was the ratio of the observed fluorescence intensities at $510 \mathrm{~nm}$ with excitation wavelengths of 340 and $380 \mathrm{~nm}$.

For calcium determinations, the fluorescence intensity resulting from excitation of fura-2-loaded growth cones at 340 and $380 \mathrm{~nm}$ were determined using a silicon-intensified target camera (Dage MTI model 66 SIT camera). The camera output was fed to a digital image processor (Image1/AT) running on a host Club $1800 \mathrm{AT}$ computer. Typically, 16 video frames were averaged at each excitation wavelength. Excitation filters were changed manually, resulting in an acquisition time of approximately $3 \mathrm{sec}$ for a pair of $340-$ and $380-\mathrm{nm}$ images. These raw images were stored on the computer hard disk drive and, at the conclusion of the experiment, were corrected for background fluorescence. Background images were obtained from a cell-free portion of the culture dish. Ratio images were then calculated for each corresponding image pair on a pixel-by-pixel basis. Because both the background image and the fluorescence image are digitized, the result of any given subtraction is subject to a certain degree of error based on the signal-to-noise ratio present in the original images. Because the images that result from excitation at $340 \mathrm{~nm}$ are relatively dim with respect to the background fluorescence intensity, the calcium concentrations reported here are subject to approximately a $10 \%$ error. The typical magnifications used resulted in a spatial resolution of approximately 4 pixels $/ \mu \mathrm{m}$. Ratio images were displayed as pseudocolor images from which cstimates of intracellular free calcium were made. All calcium estimates were based on the unweighted average of a minimum of 100 pixels. Deesterification 
of the indicator dye was verified at the conclusion of each experiment by monitoring the decrease in fluorescence intensity at $380 \mathrm{~nm}$ after the addition of either $5 \mu \mathrm{M}$ ionomycin or $50 \mathrm{~mm} \mathrm{KCl}$.

Fura-2 loading. Cultures were loaded with the fluorescent calcium indicator dye fura- 2 by incubation with the acetoxymethyl ester (AM) form of the dye dissolved in HEPES-buffered F12. The best results were obtained with a loading concentration of 1-2 $\mu \mathrm{M}$ fura-2/AM (Molecular Probes) for $90 \mathrm{~min}$ at $37^{\circ} \mathrm{C}$ followed by a $60-\mathrm{min}$ incubation at $37^{\circ} \mathrm{C}$ in the same medium without fura-2/AM to allow the cells to deesterify the indicator dye. The fura-2/AM loading medium was prepared from a fresh 1-mM stock of fura-2/AM in anhydrous dimethylsulfoxide (DMSO).

Preparation of crude collapsing activity. The preparation of a crude growth cone collapsing activity from E10 chick brain membranes has been described (Raper and Kapfhammer, 1990). Briefly, E10 chick brain membranes were solubilized in 2\% CHAPS detergent in balanced saline and pelleted at $100,000 \times g$, and the resulting supernatant was dialyzed first against phosphate-buffered saline and then against fresh F12 medium. This material was prepared fresh daily and maintained at $4^{\circ} \mathrm{C}$ until approximately $5 \mathrm{~min}$ before use, when it was warmed to $37^{\circ} \mathrm{C}$ and added into the culture as a 1:10 final dilution. The final protein concentrations were between approximately 200 and $400 \mu \mathrm{g} / \mathrm{ml}$.

Culture bath applications. To insure rapid mixing and to minimize temperature oscillations, all reagents added to cultures were added as dilute stocks in $0.5-1.0-\mathrm{ml}$ volumes of fresh HEPES-buffered F12 medium to achieve the desired final bath concentration. Reagents were warmed to $37^{\circ} \mathrm{C}$ prior to addition to the cultures. Additions were made into the side of the $35-\mathrm{mm}$ dish using a Pasteur pipette. Experiments in which temperature varied (greater than $\pm 1.5^{\circ} \mathrm{C}$ ) were discarded. Ionomycin (Calbiochem) was prepared fresh from a 10 -mM stock in anhydrous DMSO.

Collapse assay. Explanted DRG were grown in laminin-coated (10 $\mu \mathrm{g} / \mathrm{ml}$ ) 24-well tissue culture dishes (Nunc) for 18-24 hr in complete F1 2 medium. The medium was exchanged with serum-free $F 12$ or low $\mathrm{Ca}^{2+} \mathrm{F} 12$, and the cells were allowed to reequilibrate for $60 \mathrm{~min}$ at $37^{\circ} \mathrm{C}$. Drugs were added from concentrated stocks in F12 and mixed by gentle pipetting. After $5 \mathrm{~min}$, an aliquot of the crude collapsing activity was added into the culture (1:10 dilution), and the cultures were returned to the incubator. After $30 \mathrm{~min}$, several representative video fields were recorded from both control and experimental wells. These images were then scored for the number of growth cones that displayed a broad, flattened morphology and for the number of growth cones that appeared to be collapsed.

Morphometric analysis. All morphometric analyses were made using software available in the Image 1/AT system using either videotape records that were played back into the computer frame memory or images saved directly onto the computer hard disk.

\section{Results}

Under the culture conditions used in the present study, DRG growth cones are typically $15-20 \mu \mathrm{m}$ in diameter with a large veil region and numerous filopodia (see Figs. 7, 10). Individual growth cones advance at very steady rates that range between growth cones from approximately 40 to $120 \mu \mathrm{m} / \mathrm{hr}$. Using the culture conditions described here, we are able to obtain 40 or more fura-2 ratio measurements of calcium levels in individual chick DRG growth cones without affecting growth cone morphology, growth cone motility, or the rates of growth cone advance. Significant phototoxicities (inhibition of elongation and motility of the growth cone) began to become apparent if more than 40-50 ratio measurements were taken. For this reason, it was not possible to obtain both phase-contrast and fluorescence images from the same growth cone without causing some degree of photodamage. Therefore, growth cone morphology was monitored using $380-\mathrm{nm}$ images.

Calcium levels determined in motile and advancing DRG growth cones were found to have a normal distribution around a mean of $87.3 \pm 25.2 \mathrm{nM}$ (mean $\pm \mathrm{SD} ; n=87$ ) and ranged between 40 and $160 \mathrm{nM}$. Calcium levels within individual advancing growth cones appear relatively stable over time (Fig.

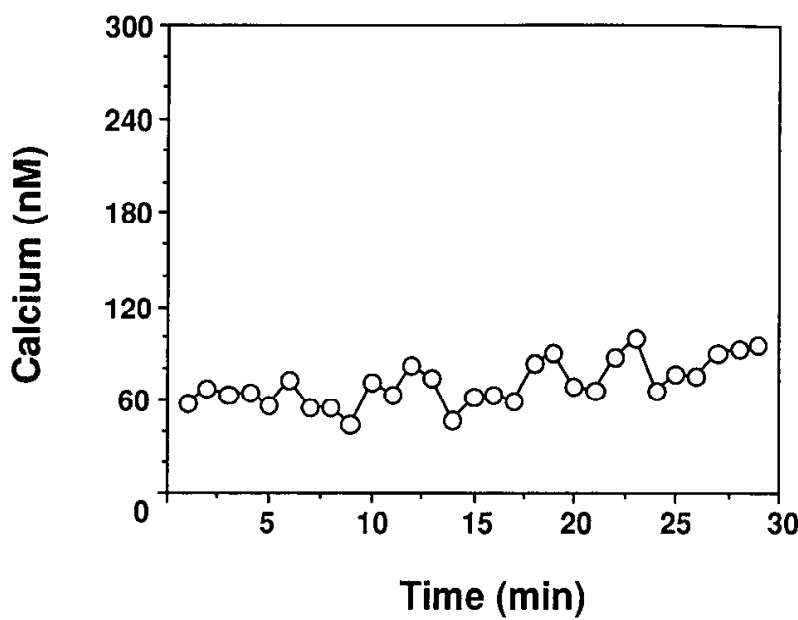

Figure 1. Calcium levels during DRG growth cone advance: $340 \mathrm{~nm}$ and $380 \mathrm{~nm}$ image pairs were taken at 1-min intervals; ratio images were calculated and used to generate estimates of growth cone calcium levels in a motile and advancing DRG growth cone.

1). However, on rare occasions, calcium levels were elevated in spontaneously branching growth cones (see Fig. 5). Calcium appeared to be homogeneously distributed in most DRG growth cones (Fig. 2a,b); however, calcium inhomogeneities were observed in $10-15 \%$ of the DRG growth cones (Fig. $2 c, d$ ). When inhomogeneities were observed, calcium levels in the veil region of the growth cone were typically elevated $20-40 \%$ relative to calcium levels in the core region of the growth cone. These calcium gradients appeared to be stable for at least $30 \mathrm{~min}$.

\section{Effect of contact between $D R G$ growth cones and $D R G$ neurites on $D R G$ growth cone calcium levels}

When the growth cones of DRG neurons encounter the neurites of other DRG neurons, they typically cross the neurite without any significant delay in crossing time or any obvious morphological response by the growth cone (Kapfhammer and Raper, 1987; present results; data not shown). Fura-2 measurements of calcium levels in the DRG growth cones indicated that, during contact and crossing, the growth cone calcium levels remained within the normal range of calcium levels observed in DRG growth cones ( $n=3$; Fig. 3 ).

\section{Effect of contact between $D R G$ growth cones and retinal neurites on DRG growth cone calcium levels}

When the growth cones of DRG neurons encounter the neurites of retinal ganglion cells, they typically experience a significant delay in their crossing time. This delay is associated with a paralysis of growth cone motility and the subsequent collapse of growth cone structure (Kapfhammer and Raper, 1987; present results; data not shown). Fura-2 measurements of calcium levels in DRG growth cones during this period of cell-cell contact and subsequent collapse of growth cone structure indicated that, during contact and collapse, growth cone calcium levels did not change significantly but remained within the normal range of calcium levels seen in motile DRG growth cones (Figs. 4,5 ). Comparable results have been obtained for retinal growth cones as they collapse on contact with DRG neurites (Fig. 5B). In every instance in which a growth cone contacted a heterotypic neurite and collapsed its structure $(n=6)$, calcium levels remained stable.

During the course of these experiments, two observations 

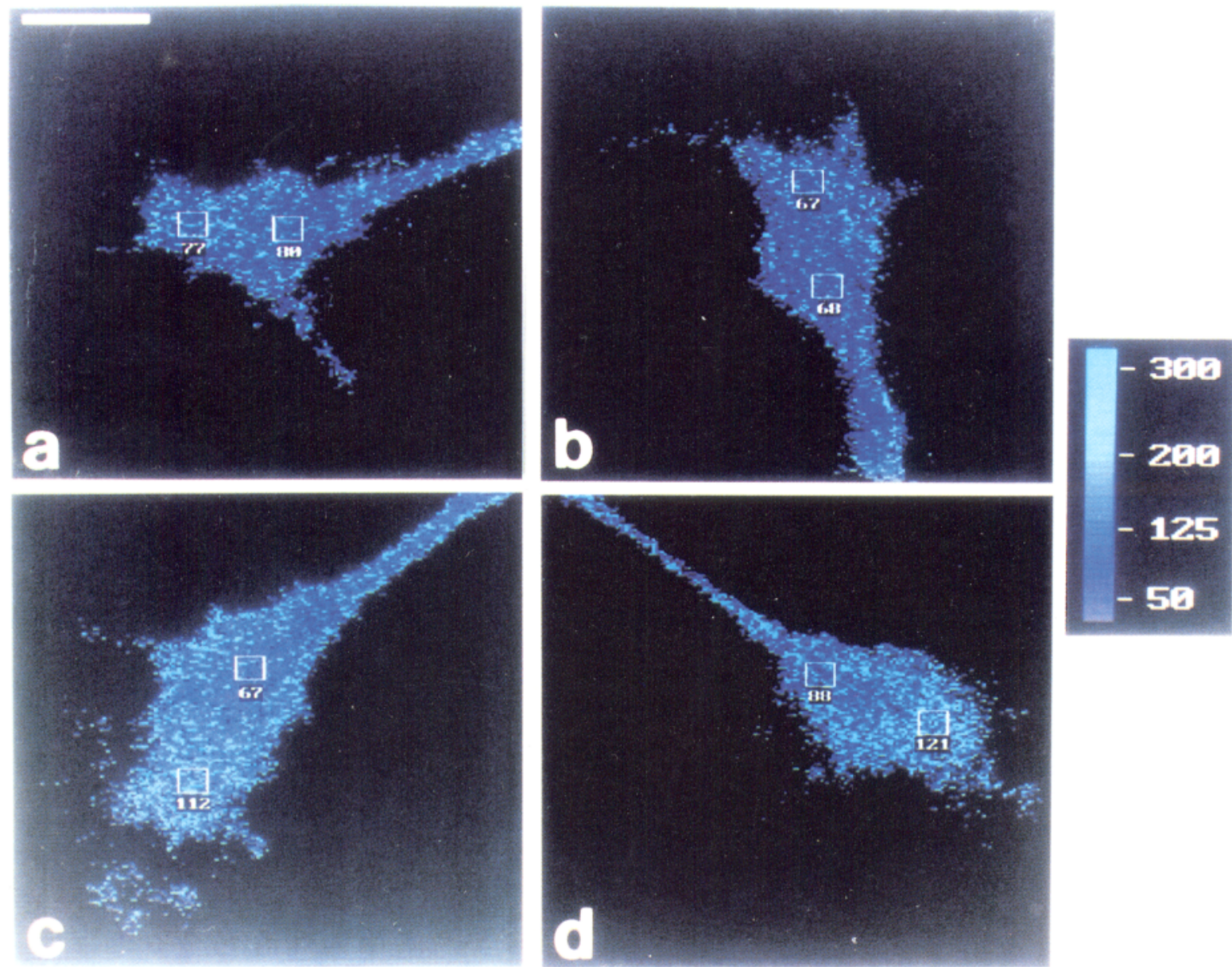

Figure 2. Distribution of calcium within chick DRG growth cones. $a$ and $b$ are ratio images of DRG growth cones in which calcium appears homogeneously distributed. $c$ and $d$ are ratio images of DRG growth cones in which calcium gradients are apparent. Calcium concentrations (in nм) are indicated within the boxed areas. In $a$, calcium is $80 \mathrm{~nm}$ near the base of the growth cone and $77 \mathrm{~nm}$ in the veil region. In $b$, calcium is $68 \mathrm{~nm}$ near the base of the growth cone and $67 \mathrm{~nm}$ in the veil region. In $c$, calcium ranges from $67 \mathrm{~nm}$ near the base to $112 \mathrm{~nm}$ in the veil region. In $d$, calcium ranges from $88 \mathrm{~nm}$ near the base to $121 \mathrm{~nm}$ in the veil. Such gradients of calcium were stable for at least $30 \mathrm{~min}$. Scale bar, $10 \mu \mathrm{m}$.

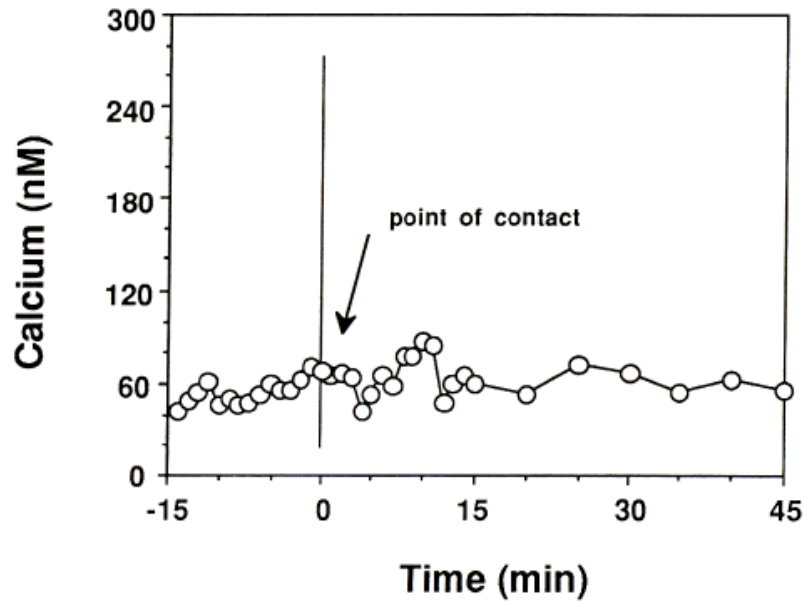

Figure 3. Effect of contact between DRG growth cone and DRG neurite on growth cone calcium levels. Growth cone calcium levels were determined at approximately 1 -min intervals as a DRG growth cone advanced toward, contacted, and crossed a DRG neurite. The point of initial contact is indicated by the solid vertical line. The growth cone remained motile and continued to advance throughout the entire scquence. were made of growth cones spontaneously bifurcating to form two new growth cones. For example, prior to any cell-cell contact, the growth cone in Figure $5 A$ branches to form two growth cones. During this time, growth cone calcium was significantly elevated. After branching and prior to cell contact, however, growth cone calcium levels returned to basal values. This observation suggests that DRG growth cones can perhaps modulate their intracellular calcium levels under some circumstances (e.g., branching). However, changes in calcium are not associated with contact-mediated growth cone collapse.

\section{Effect of calcium ionophore on DRG growth cone motility and calcium levels}

Because intracellular levels of $\mathrm{Ca}^{2+}$ did not appear to change during the collapse of growth cone structure, it was important to determine how much of a change in calcium was required to cause DRG growth cone collapse. Therefore, using time-lapse video microscopy, a maximal concentration of the calcium ionophore ionomycin was defined that could be applied to the culture media without affecting growth cone morphology, growth cone motility, or rates of growth cone advance. Concentrations of the calcium ionophore ionomycin up to and including $1 \mu \mathrm{M}$ did not affect the rate of DRG growth cone advance $(n=14$ 

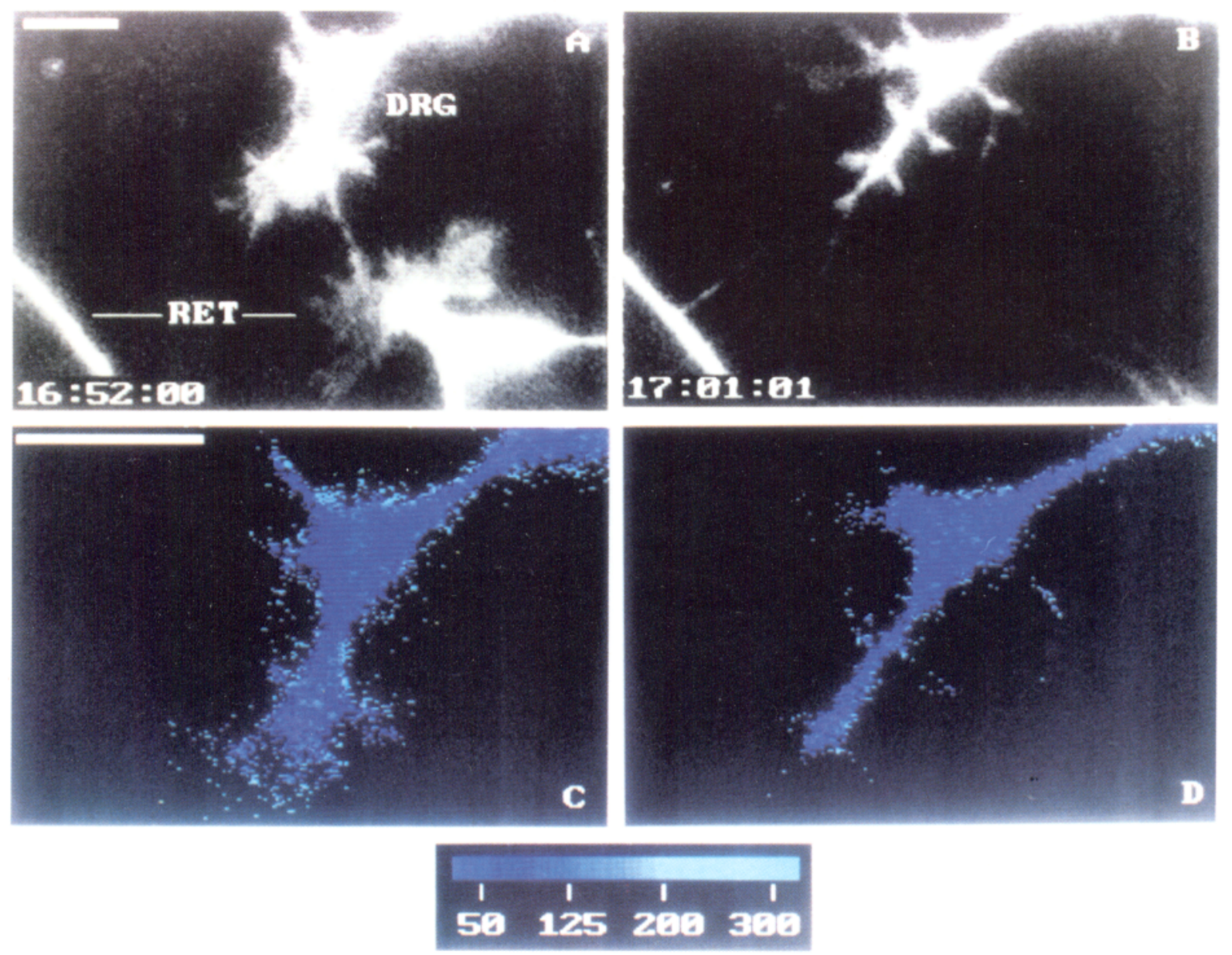

Figure 4. Effect of contact between DRG growth cone and retinal neurite on growth cone morphology and calcium levels. In $a$, a 380 -nm image of DRG at time of filopodial contact with retinal neurite is shown. $b$ shows that, 8 min later, the DRG growth cone has collapsed. $c$ and $d$ are ratio images of DRG growth cone corresponding to $a$ and $b$. For clarity, the ratio images have been enlarged digitally twofold. Scale bars, $10 \mu \mathrm{m}$.

growth cones in nine cultures; Fig. 6). Furthermore, the presence of $1 \mu \mathrm{M}$ ionomycin did not affect growth cone morphology (Fig. 7). Filopodia remained intact, rates of filopodial extension and withdrawal appeared normal, and the veil region maintained a normal phase-contrast appearance. Application of $1 \mu \mathrm{M}$ ionomycin to fura-2-loaded growth cones caused a significant increase in growth cone calcium (Fig. 8). Typically, over the course of 2-4 min, calcium levels were increased two- to threefold above basal values (from $70 \pm 21$ to $216 \pm 58 \mathrm{~nm}$, mean \pm $\mathrm{SD} ; n=5$ ). Over the next 5-10 min, calcium levels returned to a new stable state, but remained somewhat elevated relative to preionophore levels. Because calcium levels could be increased threefold without obvious effects on growth cone structure and motility, this suggested that the collapse of DRG growth cone structure following contact with a retinal neurite was not due to a small change in intracellular free calcium that went undetected.

Higher concentrations of ionomycin (2.5-5 $\mu \mathrm{M})$ invariably caused a rapid and complete cessation of all growth cone motility (data not shown). Occasionally, this was associated with a collapse of growth cone structure and retraction of the neurite, though this was not a consistent observation. When calcium levels were measured during exposure to these high concentrations of ionophore, calcium would rapidly rise (1-2 $\mathrm{min})$ to a plateau level of approximately $400 \mathrm{~nm}$, remain at that level for between 1 and $3 \mathrm{~min}$, then rise dramatically to levels well exceeding $1 \mu \mathrm{M}$. In the continued presence of ionophore, recovery of motility or restoration of growth cone calcium to levels approaching basal were never observed.

\section{Effect of potassium depolarization on DRG growth cone motility and calcium levels}

Again, using time-lapse video microscopy, a maximal concentration of $\mathrm{KCl}$ was defined that, when added directly to the culture media, would have no effect on growth cone motility or morphology. Depolarization of DRG growth cones with $15 \mathrm{~mm}$ $\mathrm{KCl}$ did not affect the rate of growth cone advance (Fig. 9; $n=$ 17 growth cones in 11 cultures), nor did it have significant effects on growth cone morphology (Fig. 10). In 11 of the 17 growth cones observed, there was no morphological response to the $\mathrm{K}^{+}$induced depolarization. In the remaining six cases, however, a transient lamellipodial ruffling was evident. When applied to fura-2-loaded growth cones, $15 \mathrm{~mm} \mathrm{KCl}$ elicited rapid but transient increases in growth cone calcium levels (Figs. 11, 12). Calcium typically rose two- to threefold above basal levels, reaching peak values (from $103 \pm 33$ to $234 \pm 75 \mathrm{~nm}$, mean \pm $\mathrm{SD} ; n=8$ ) between 30 and $60 \mathrm{sec}$. By $90 \mathrm{sec}$, calcium levels had typically returned to predepolarization values. $\mathrm{NaCl}(15$ 

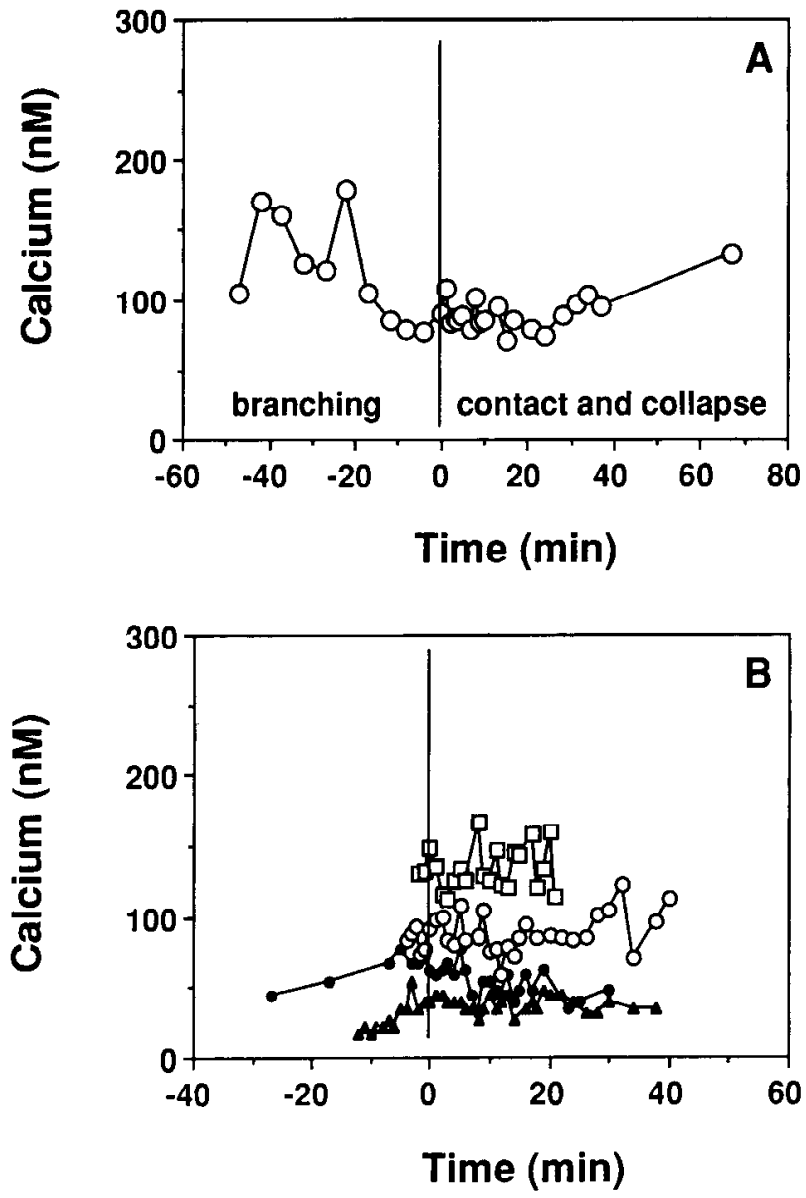

Figure 5. Calcium levels during contact-mediated growth cone collapse. $A$, Calcium levels were determined in a DRG growth cone as it contacts a retinal neurite and subsequently collapses. In this case, growth cone collapse was complete in $10 \mathrm{~min}$. Approximately $30 \mathrm{~min}$ prior to contact, the growth cone branches. During this time, calcium is elevated in the growth cone. However, calcium returns to basal levels prior to contact and remains there during contact and collapse. $B$, Calcium levels in two DRG growth cones (open symbols) contacting retinal neurites and two retinal growth cones (solid symbols) contacting DRG neurites are shown as a function of time. Cells with different basal levels of calcium were chosen so that individual records could be followed on the same graph. In each panel, contact is indicated by the solid vertical line.

$\mathrm{mM}$ ) did not cause changes in growth cone calcium levels (data not shown), suggesting that the calcium transients were caused by cellular depolarization rather than increased ionic strength.

\section{Effect of a crude growth cone collapsing activity on $D R G$ growth cone calcium levels}

A detergent extract of $\mathrm{E} 10$ chick brain that contains one or more protein components with growth cone collapsing activity (Raper and Kapfhammer, 1990) was applied to cultures of DRG neurons. Although the specific activity of this material varies slightly from preparation to preparation, $85-90 \%$ of DRG growth cones collapse when exposed to it. By morphological criteria, growth cone collapse is typically complete within $15 \mathrm{~min}$. Fura-2 measurements of DRG growth cones collapsed by exposure to this material $(n=7)$ did not indicate significant changes in growth cone calcium levels (Figs. 13, 14). Unlike the growth cone collapse that occurred in cocultures, the initiation of growth

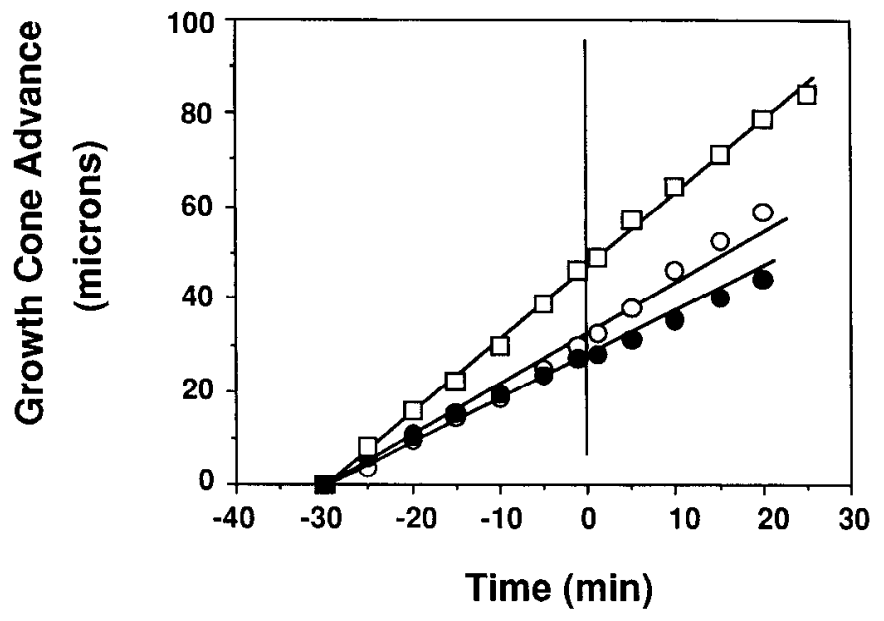

Figure 6. Effect of $1 \mu \mathrm{M}$ ionomycin on rates of growth cone advance. Rates of growth cone advance were determined from continuous video recordings and plotted as a function of time. Ionomycin $(1 \mu \mathrm{M})$ was added to the bathing medium at time 0 min as indicated by the solid vertical line. The results of three representative experiments are shown.

cone collapse could be precisely timed by the addition of collapsing activity. Therefore, the emission from $380-\mathrm{nm}$ excitation of fura-2-loaded growth cones was monitored at video rates (30 frames/sec) to determine if calcium transients were occurring at rates faster than could be detected by the ratio method. These experiments provided no evidence to suggest that rapid changes in calcium (either increases or decreases) were occurring that were missed by the ratio determinations ( $n=3$; data not shown).

It should be pointed out that shape changes or volume changes will cause the fluorescence intensity measured at a single wavelength to change in the absence of a change in calcium concentration. Therefore, these single wavelength measurements must be viewed as qualitative observations. Nonetheless, a large decrease in 380-nm fluorescence intensity is seen when growth cones are depolarized with $15 \mathrm{~mm} \mathrm{KCl}$, while no significant change is seen with the crude collapsing activity. These results, though qualitative, are entirely consistent with the results of the more quantitative ratio determinations.

\section{Effect of calcium channel blockers on the crude growth cone collapsing activity}

To determine whether calcium influx was required for growth cone collapse caused by the crude collapsing activity, collapse assays were performed in the presence of scveral calcium channel antagonists. The calcium channel blockers lanthanum (100 $\mu \mathrm{M})$, nickel $(100 \mu \mathrm{M})$, cobalt $(100 \mu \mathrm{M})$, and nifedipine $(50 \mu \mathrm{M})$, as well as medium prepared with no added calcium, failed to inhibit significantly the extent of growth cone collapse caused by the application of the crude chick-brain-derived growth cone collapsing activity to chick DRG growth cones (Fig. 15).

The increased percentage of growth cone collapse that occurs in the presence of each of these calcium antagonists compared to controls (cf. Fig. 15, dark bars) suggests a toxic effect of the calcium blockers on chick DRG growth cones. For this reason, four different calcium channel blockers were employed. Similar results were obtained with each calcium antagonist, as well as in reduced-calcium medium. Although the percentage of growth cones that appeared to be collapsed in each of the control conditions was slightly elevated compared to growth cones ad- 

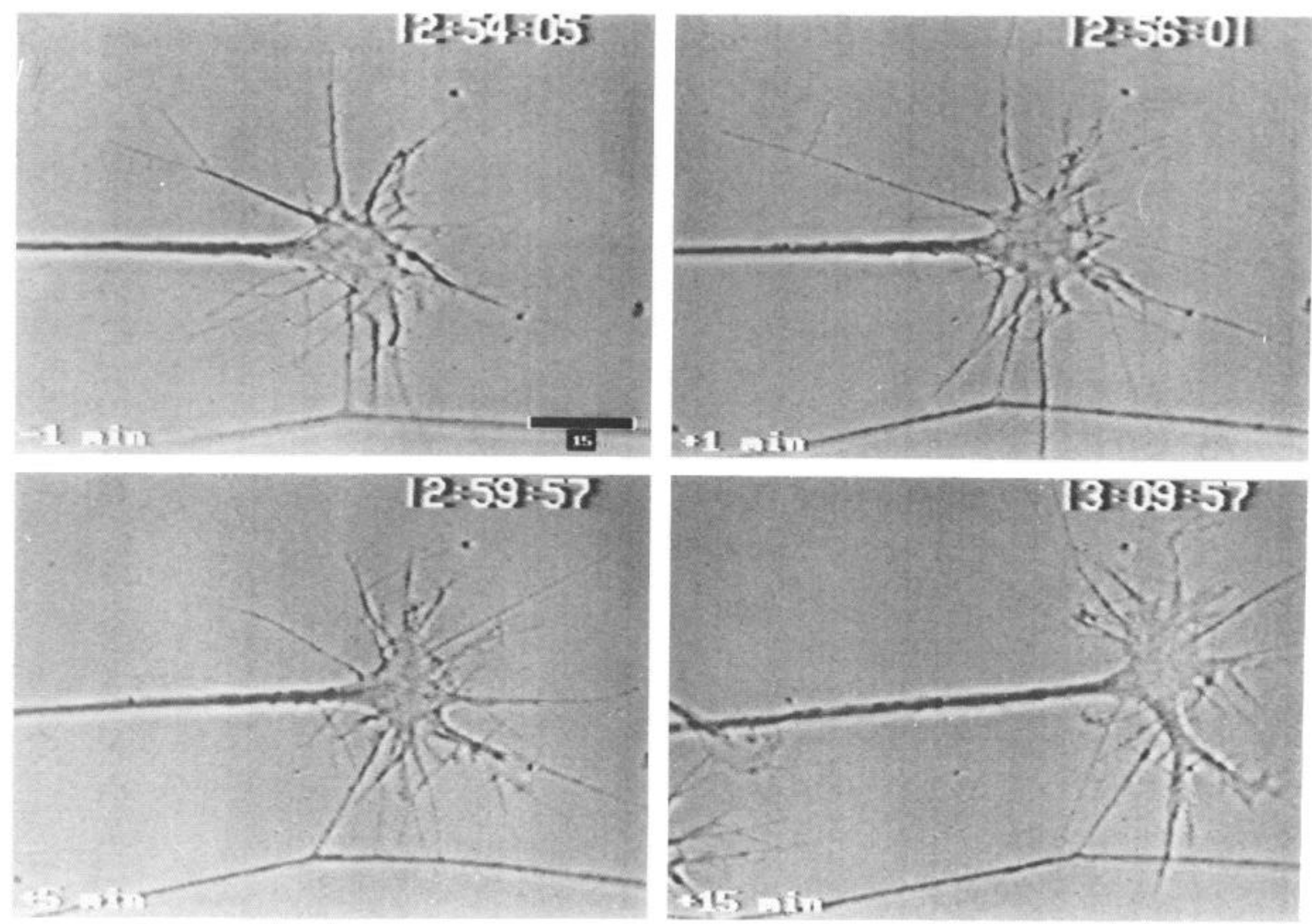

Figure 7. Effect of $1 \mu \mathrm{M}$ ionomycin on growth cone morphology. A DRG growth cone was exposed to $1 \mu \mathrm{M}$ ionomycin at time 0 min (12:55:00). Filopodia and lamellipodia are present and active $1 \mathrm{~min}$ before and $1 \mathrm{~min}$ after addition of the ionophore. At $5 \mathrm{~min}$ and $15 \mathrm{~min}$, the growth cone morphology is still normal, and the growth cone has continued to advance. Scale bar, $15 \mu \mathrm{m}$.

vancing in normal culture medium, none of these calcium antagonists significantly interfered with the extent of growth cone collapse caused by the growth cone collapsing activity, suggesting that calcium influx is not a necessary feature of the mechanism of growth cone collapse.

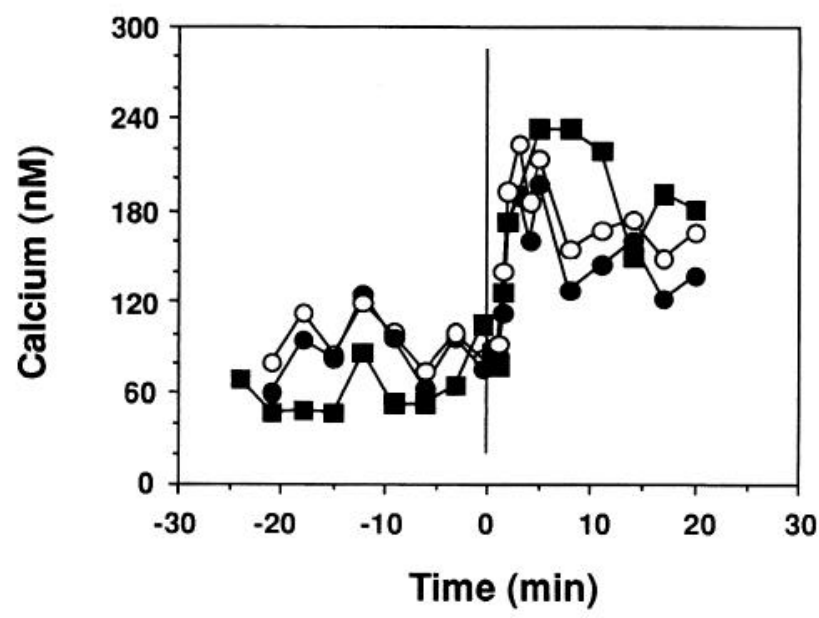

Figure 8. Effect of $1 \mu \mathrm{M}$ ionomycin on growth cone calcium levels. Growth cone calcium levels were determined before and after the addition of $1 \mu \mathrm{M}$ ionomycin at time $0 \mathrm{~min}$ to the culture medium. The results of three representative experiments are shown.

\section{Discussion}

The fluorescent calcium indicator dye fura- 2 and high-resolution low-light-level digital imaging fluorescence microscopy have been used to examine the distribution of free calcium in chick

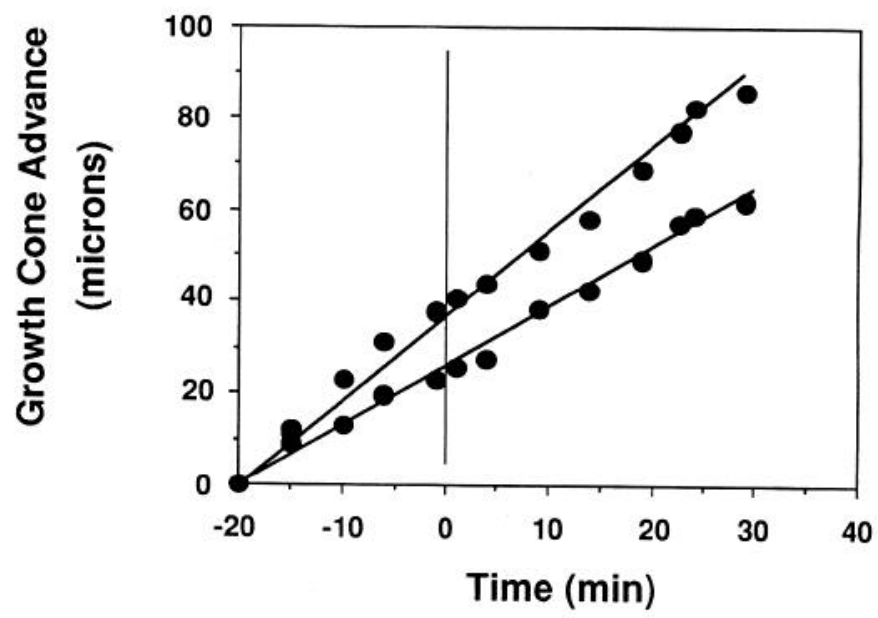

Figure 9. Effect of $15 \mathrm{~mm} \mathrm{KCl}$ on rates of growth cone advance. Rates of growth cone advance were determined from continuous video recordings and plotted as a function of time. The culture was depolarized with $15 \mathrm{~mm} \mathrm{KCl}$ at time $0 \mathrm{~min}$ as indicated by the solid vertical line. The results of two representative experiments are shown. 

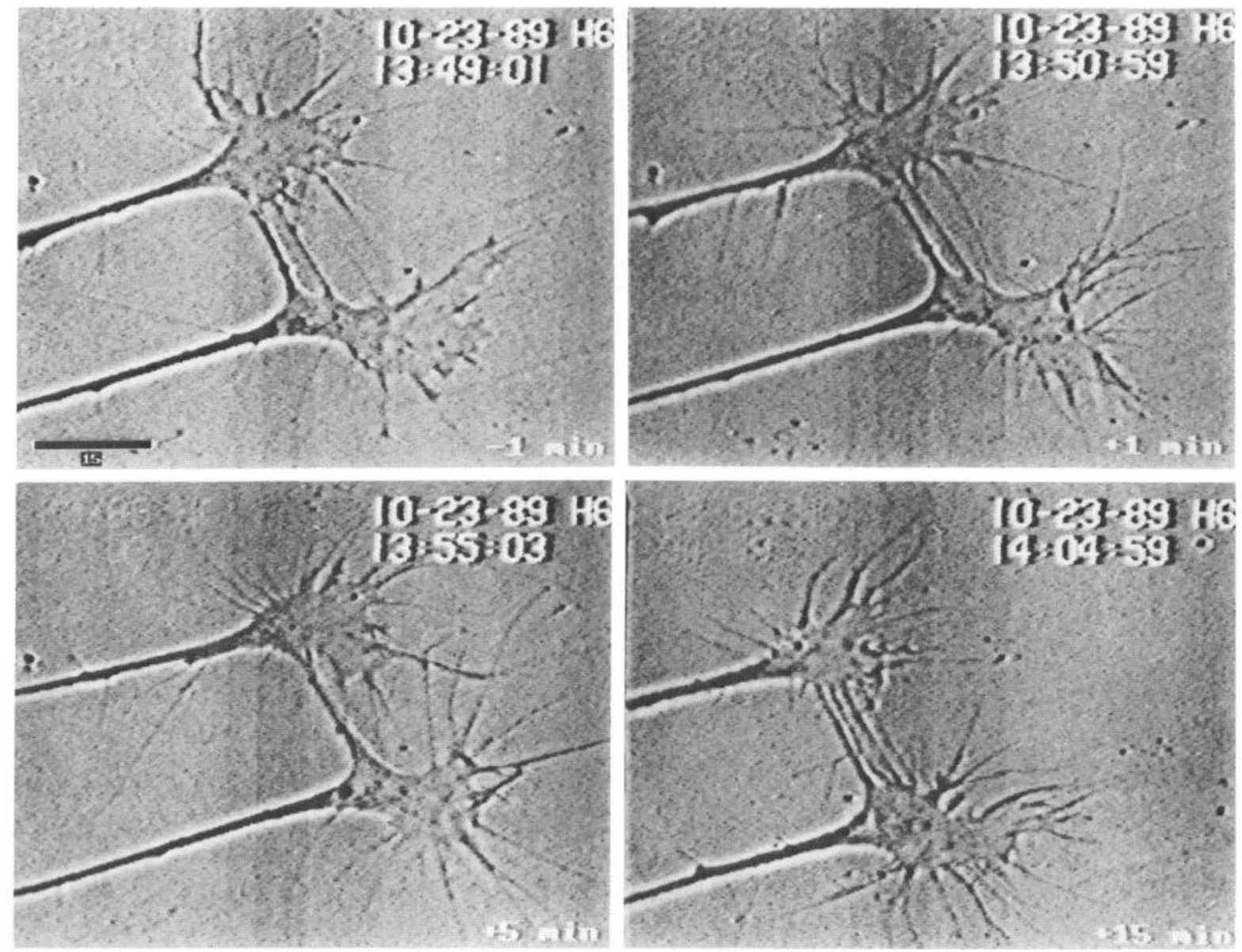

Figure 10. Effect of $15 \mathrm{~mm} \mathrm{KCl}$ on growth cone morphology. Panels from a video recording in which two DRG growth cones were depolarized with the addition of $15 \mathrm{~mm} \mathrm{KCl}$ to the culture medium are shown. Growth cones remain broad and flattened, with active filopodia and lamellipodia, and continue to advance after depolarization with $15 \mathrm{~mm} \mathrm{KCl}$. The field shifts to the right at $15 \mathrm{~min}$. Scale bar, $15 \mu \mathrm{m}$.

DRG growth cones, to determine if changes in free calcium are associated with the contact-mediated collapse of growth cone structure, and to determine the effects of changing calcium on growth cone motility and morphology. Calcium appeared to be

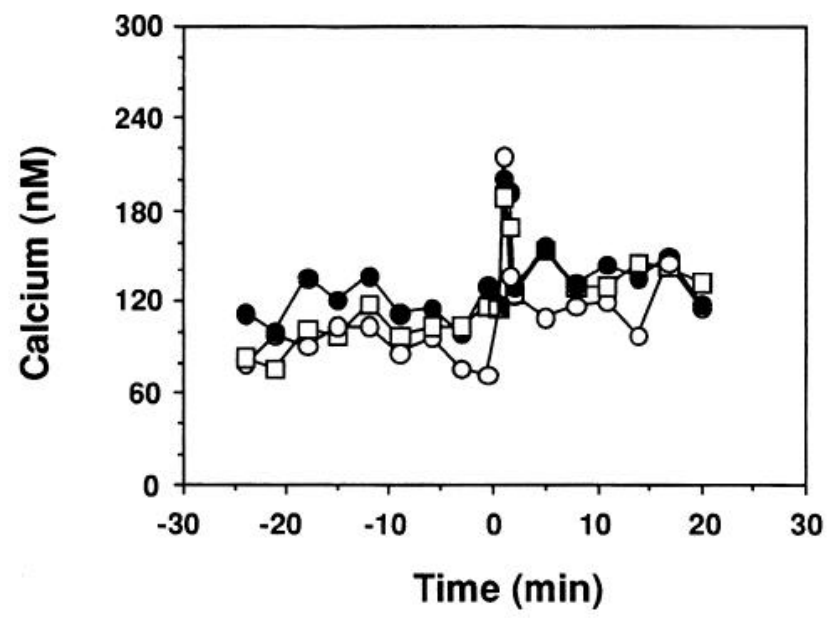

Figure 11. Effect of $15 \mathrm{~mm} \mathrm{KCl}$ on growth cone calcium levels. Growth cone calcium levels were determined before and after exposure to 15 $\mathrm{mm} \mathrm{KCl}$. Depolarization occurred at time $0 \mathrm{~min}$. The results of three separate experiments are shown. homogeneously distributed in the majority $(>85 \%)$ of the growth cones examined. When calcium gradients were observed (Fig. 2 ), the highest levels were invariably seen in the veil regions of the growth cones. When present, these gradients would persist for the duration of the imaging experiment. This is in contrast to observations of Helisoma growth cones, in which higher calcium levels are seen in the core region than at the leading edge (Mills and Kater, 1989; Rehder et al., 1989). The growth cones of N1E-115 neuroblastoma cells also appear to have slightly lower calcium levels in the veil than in the core region of the growth cone (Silver et al., 1989). There are several possible explanations for these observed differences. First, cell-type-specific differences in the location of sites of calcium entry and in the location and efficiency of calcium efflux and sequestration mechanisms may result in different spatial distributions of intracellular free calcium. Second, high-resolution phase-contrast images of neuroblastoma (Silver et al., 1989) and Helisoma growth cones (Haydon et al., 1985) indicate that they are typically very rich in organelles. Such organelles may compartmentalize fura-2, thus causing high cytosolic calcium estimates (Cobbold and Rink, 1987). The chick growth cones in this study, however, appear relatively organelle poor at the resolution of phase-contrast microscopy (Figs. 7, 10), and fluorescence images of dye-loaded growth cones give the appearance that fura- 2 is homogeneously distributed within the growth cone and not se- 

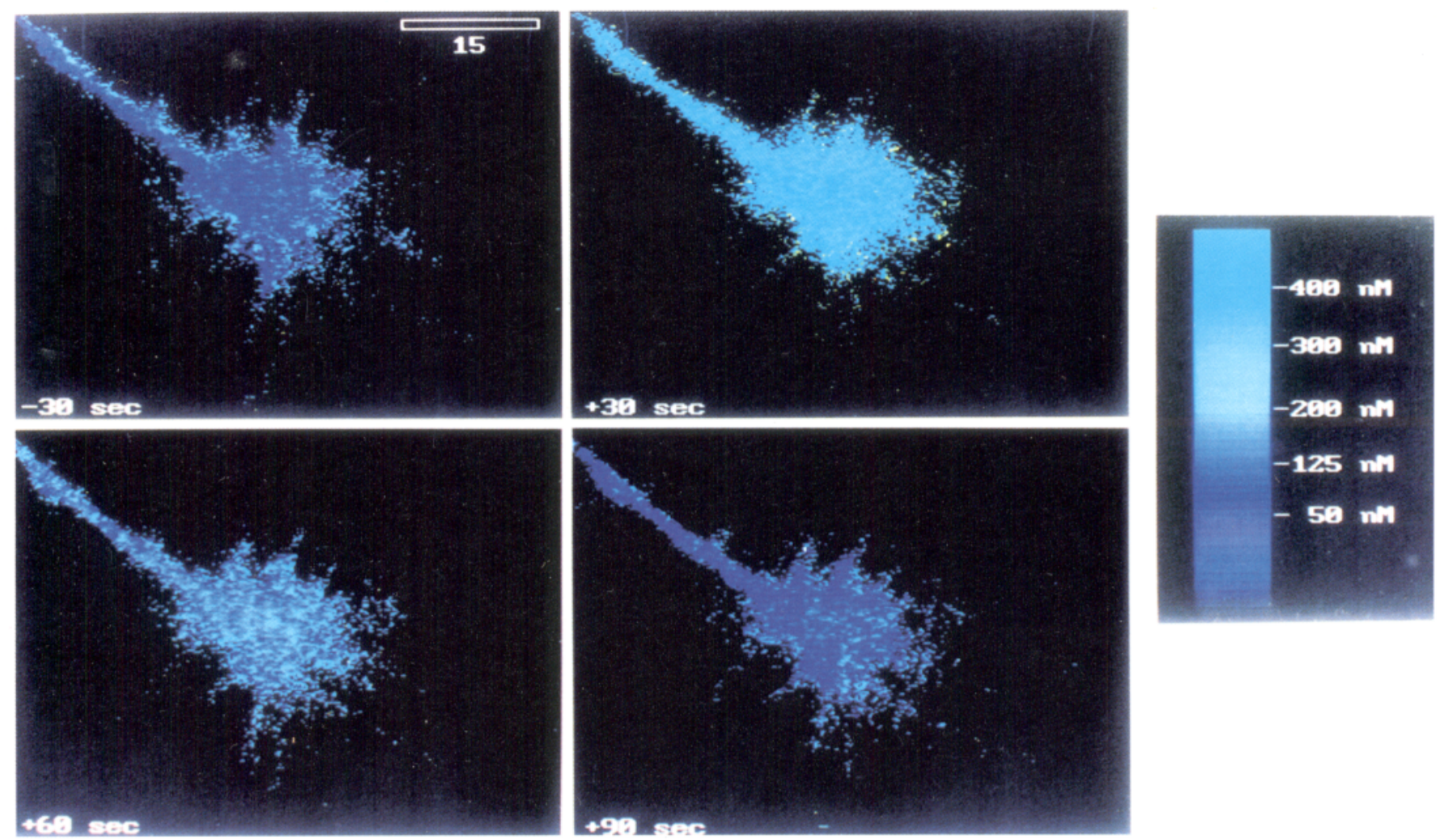

Figure 12. Ratio images of growth cone calcium levels during $\mathrm{KCl}$ depolarization: 340 and $380 \mathrm{~nm}$ image pairs were collected at 30 -sec intervals before and after depolarization with $15 \mathrm{~mm} \mathrm{KCl}$. The resulting ratio images are shown. Scale bar, $15 \mu \mathrm{m}$.

questered into subcellular compartments. Finally, it must be pointed out that these veils are extremely thin, and the corresponding fluorescence signals are weak and therefore may be subject to error.

Several studies have localized calcium channels and calcium currents to the veil regions and to the base of filopodia (Anglister et al., 1982; Freeman et al., 1985; O'Lague et al., 1985; Lipscombe et al., 1988; Silver et al., 1990). Therefore, one might expect to find higher levels of free calcium near these calcium entry zones. The observations of Goldberg (1988) that veil formation in Aplysia growth cones growing in low-calcium medium occurs preferentially toward a local source of high calcium is also consistent with the view that calcium entry occurs near the veil region and is important for veil formation. Chick DRG growth cones will also turn toward a micropipette containing low concentrations of a calcium ionophore (Gundersen and Barrett, 1980). Interestingly, rat sympathetic neurons will continue to extend axons for several days when cultured in the virtual absence of extracellular calcium (Campenot and Draker, 1989) or under conditions that do not allow the generation of calcium transients (Tolkovsky et al., 1990). Because intracellular free calcium was homogenously distributed in the majority of DRG growth cones examined in this study, the functional significance of these calcium gradients in a small number of growth cones is not clear.

Recent data has accumulated to suggest that calcium is an important regulator of many growth cone functions (Cohan et al., 1987; Mattson and Kater, 1987; Kater et al., 1988). Specifically, the inhibitory effects of 5-HT on Helisoma neuron B19 are mediated through calcium, as are the effects of voltage and ionophores. Many of the morphological features of growth cone collapse that we have observed (Kapfhammer and Raper, 1987; Ivins and Pittman, 1989) suggested possible roles for calcium in mediating growth cone collapse. Changes in levels of calcium may be able to alter both actin (Schliwa et al., 1981; Lankford and Letourneau, 1989; Downey et al., 1990) and tubulin (Yamamoto et al., 1983) polymerization states, affect the activity of growth cone myosin (Bridgman and Dailey, 1989), and regulate the interaction of the actin cytoskeleton with membrane linkages such as spectrin (Harris and Morrow, 1990). Any of these effects on the growth cone cytoskeleton could conceivably lead to growth cone collapse. Therefore, it was of interest to determine if significant changes in growth cone calcium levels occur when the growth cones of chick DRG neurons encounter the neurites of chick retinal ganglion cells in vitro and subsequently collapse.

During growth cone advance, cell-cell contact, and growth cone collapse, the calcium levels within the collapsing DRG growth cones are remarkably stable. These results were somewhat surprising and made several additional control experiments necessary in order to address uncertainties about the absolute sensitivity of the imaging system to detect changes in growth cone calcium. Specifically, it seemed possible that small yet significant changes in calcium levels or rapid transients of calcium in growth cones occurred but escaped detection. Therefore, DRG growth cones were subjected to manipulations that were expected to cause changes in intracellular calcium levels. The effects of these manipulations on growth cone morphology, motility, and calcium levels were determined.

If small increases in calcium levels that were below the limit of detection of the assay were responsible for the growth cone collapse, it might be expected that if calcium levels were in- 


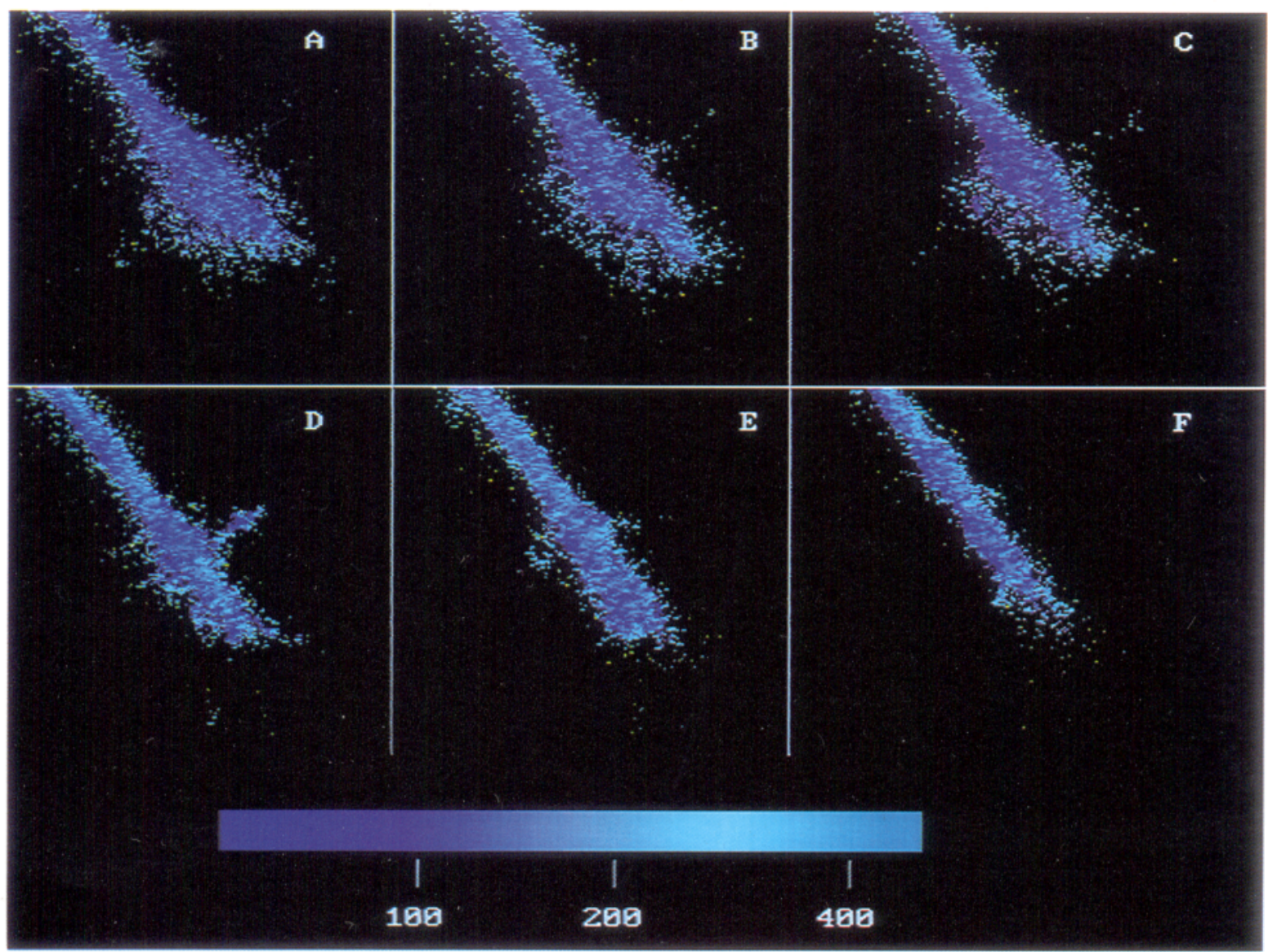

Figure 13. Ratio images of growth cone calcium levels during exposure to a soluble chick-brain-derived growth cone collapsing activity: 340 and $380 \mathrm{~nm}$ image pairs were collected before and after exposure to a crude, soluble growth cone collapsing activity. The resulting ratio images are shown. $A$, One minute prior to exposure. $B$, Thirty seconds after exposure. $C$, Two minutes after exposure. $D$, Six minutes after exposure. $E$, Ten minutes after exposure. $F$, Sixteen minutes after exposure. Color scale for calcium concentration is in nM.

creased experimentally, then the morphological features of collapse should also be produced. However, when $1 \mu \mathrm{M}$ ionomycin was applied to growth cones, two- to threefold increases in growth cone calcium were readily detected, yet there were no obvious

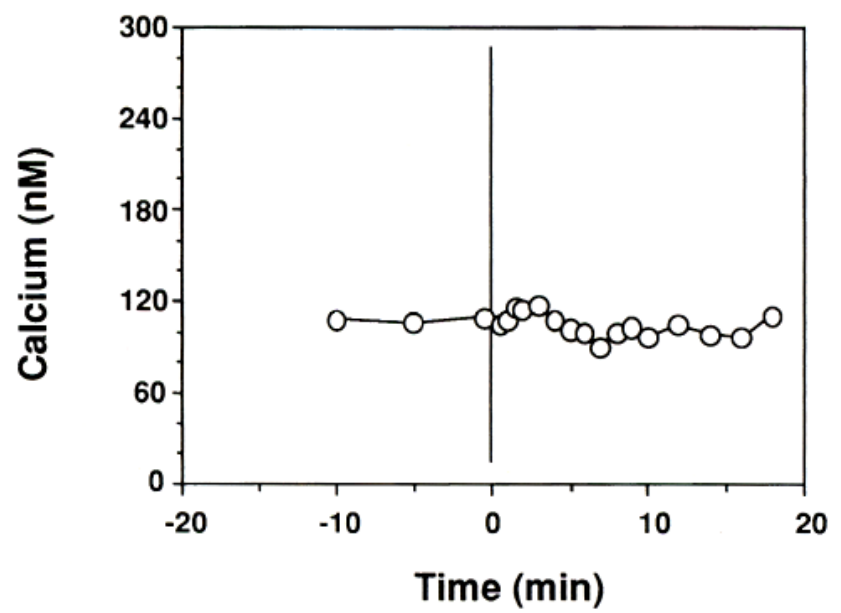

Figure 14. Effect of brain-derived growth cone collapsing activity on calcium levels in DRG growth cones. Calcium levels were determined in a DRG growth cone before and after exposure to a crude chick-brainderived growth cone collapsing activity. The material was added to the culture media at time $0 \mathrm{~min}$ as indicated by the solid vertical line. In this case, the morphological collapse was complete by $12 \mathrm{~min}$. effects on the morphology of DRG growth cones, the patterns of motility of DRG growth cones, or the rates of DRG growth cone advance. This suggests that increases in calcium large enough to have caused growth cone collapse would also have been detected by the imaging system.

If calcium transients were responsible for growth cone collapse and were occurring on a time scale faster than could reliably be measured, it would be expected that experimentally induced calcium transients would mimic the morphological features of collapse. However, depolarization of cultures by bath application of $\mathrm{KCl}$ at concentrations up to $15 \mathrm{~mm}$ caused readily detectable calcium transients in DRG growth cones yet did not have significant effects on DRG growth cone morphology or rates of advance. Higher concentrations of $\mathrm{KCl}(>20 \mathrm{~mm})$ will often cause growth cones to collapse and retract over very large distances $(30-50 \mu \mathrm{m})$. These collapses, however, appear morphologically dissimilar to those caused by cell-cell contact and occur over a much more rapid time course $(10 \mathrm{sec}$ to $1 \mathrm{~min}$; data not shown). These data suggest that, if calcium transients are responsible for growth cone collapse, they must be larger than those induced by $15 \mathrm{~mm} \mathrm{KCl}$ depolarization and therefore would also be readily detectable.

An additional concern was that, during cell-cell contact, an increase in calcium levels localized to very discrete regions of the growth cone such as a single filopodium could be the signal for growth cone collapse. Current techniques do not allow ac- 


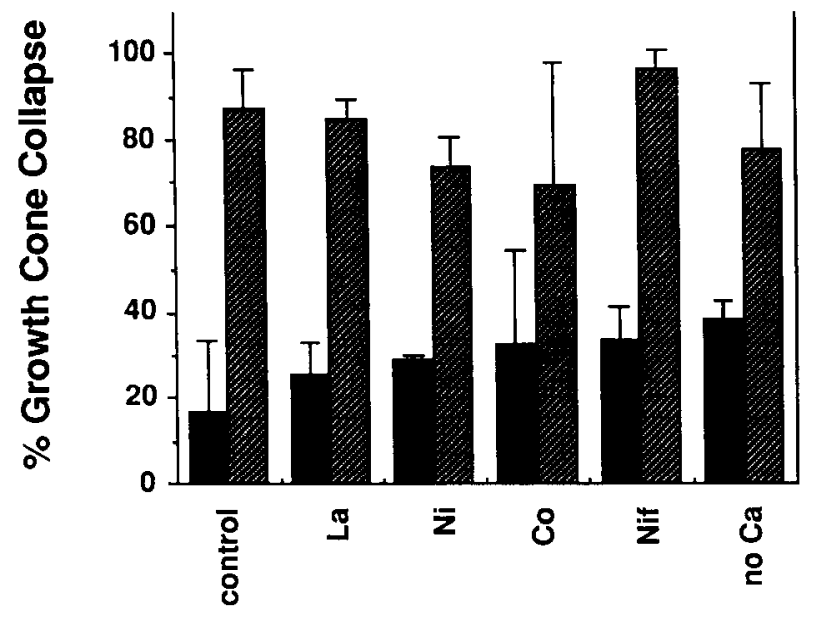

Condition

Figure 15. Effect of calcium channel antagonists on growth cone collapsing activity. DRG explants were grown in 24-well plates as described in Materials and Methods in the presence (hatched bars) or absence (solid bars) of crude collapse activity and in the presence of the indicated calcium channel blockers [lanthanum, $100 \mu \mathrm{M}(\mathrm{La})$; nickel, $100 \mu \mathrm{M}$; cobalt, $100 \mu \mathrm{M}$; nifedipine, $50 \mu \mathrm{M}(\mathrm{Nif})$ ] or medium prepared without any added calcium ( $n o \mathrm{Ca}$ ). After $30 \mathrm{~min}$, random video fields were recorded on videotape and scored for the percentage of collapsed growth cones. The results (mean $\pm \mathrm{SD}$ ) of three separate experiments are shown. Between 51 and 164 individual growth cones were scored for each condition.

curate calcium measurements in a single filopodium. The volume of a filopodium is very small with respect to the body of the growth cone, and the corresponding fluorescence signals from calcium-sensitive dyes are very weak. If growth cones were bathed in a growth cone collapsing activity, it might be expected that any resulting change in calcium levels would be detected throughout the growth cones, yet when a growth cone collapsing activity solubilized from E10 chick brain (Raper and Kapfhammer, 1990) was added to the culture medium, neither significant increases nor significant decreases in growth cone calcium levels were detected, suggesting that discrete local changes in calcium were unlikely. Because NCAM and other cell adhesion molecules have been localized on filopodia (Letourneau and Shattuck, 1989; Sheetz et al., 1990), the possibility that receptors for the collapsing activity are localized on filopodia, where they cause localized changes in calcium levels, cannot be ruled out.

Although large changes in calcium clearly can disrupt the stability of growth cone actin and cause DRG growth cones to collapse (Lankford and Letourneau, 1989; present results), smaller changes in calcium levels appear to be tolerated well by these growth cones. Calcium homeostatic mechanisms have been described in the growth cones and cell bodies of Helisoma neurons (Mills and Kater, 1990). The calcium homeostatic mechanisms operating in these DRG growth cones also seem to be very potent.

These results indicate that, if increases in calcium caused morphological features of growth cone collapse, the levels reached during contact must be greater than those observed for ionomycin and $\mathrm{KCl}$ application. These results show (1) that two- to threefold increases in calcium can be evoked in DRG growth cones, and (2) that these calcium changes were insufficient to alter the morphology or behavior of DRG growth cones. This suggests that if calcium were mediating growth cone collapse, then higher levels must be reached, yet during contact-mediated growth cone collapse, no changes in calcium levels were seen. Furthermore, calcium channel antagonists did not interfere with the activity of a crude chick-brain-derived growth cone collapsing factor, suggesting that calcium influx is not necessary for DRG growth cone collapse. Therefore, growth cone collapse in this system is unlikely to be mediated by changes in intracellular calcium.

The mechanism underlying the collapse of growth cones upon contact remains unknown. Raper and Kapfhammer (1990) have reported that growth cone collapse in response to an enriched growth cone collapsing activity occurs when either laminin or G-4 is used as the growth substrate. The CSAT antibody, which is directed against an integrin $\beta$-chain, causes detachment of DRG growth cones only when they are grown on laminin, not on G-4 (J. A. Raper, unpublished observations), suggesting that the growth cones use different molecular mechanisms to grow on these two substrates. Because growth cone collapse is not substrate dependent, it seems unlikely that a loss of adhesion between the growth cone and the substrate is the mechanism of growth cone collapse. Furthermore, both contact-mediated growth cone collapse and growth cone collapse initiated by the application of brain-derived collapsing activity are reversible, suggesting that the growth substratc has not becn modificd.

The morphological changes in growth cone structure during collapse would suggest that significant reorganization of the growth cone cytoskeleton is occurring. Future studies will attempt to determine the nature of this reorganization and will be facilitated by the molecular characterization of various collapsing activities (Cox et al., 1990; Davies et al., 1990; Raper and Kapfhammer, 1990) and their receptors. The second messenger(s) involved remains unknown. It is also not known whether the chick-brain-derived growth cone collapsing material is the same or even related to the retinal ganglion cell surface "label" that causes DRG growth cone collapse. It is clear, however, that in contrast to other growth cone stop signals that have been characterized (e.g., 5-HT, voltage), the growth cone collapsing activities examined in this study use second-messenger systems other than calcium. Therefore, second messengers other than calcium are likely to be involved in the regulation of many vertebrate growth cone behaviors.

\section{References}

Anglister L, Farber IC, Shahar A, Grinvald A (1982) Localization of voltage-sensitive calcium channels along developing neurites: their possible role in regulating neurite elongation. Dev Biol 94:351-365.

Bastiani MJ, Raper JA, Goodman CS (1984) Pathfinding by neuronal growth cones in grasshopper embryos. III. Selective affinity of the $G$ growth cone for the $P$ cells within the A/P fascicle. J Neurosci 4:23112328.

Becker PL, Fay FS (1987) Photobleaching of fura-2 and its effect on determination of calcium concentrations. Am J Physiol 253:C613C618.

Bray D (1979) Mechanical tension produced by nerve cells in tissue culture. J Cell Sci 37:391-410.

Bridgman PC, Dailey ME (1989) The organization of myosin and actin in rapid frozen nerve growth cones. J Cell Biol 108:95-109.

Burton LE, Wilson WH, Shooter EM (1978) Nerve growth factor in mouse saliva. Rapid isolation procedures for and characterization of 7S nerve growth factor. J Biol Chem 253:7807-7812.

Campenot RB, Draker DD (1989) Growth of sympathetic nerve fibers in culture does not require extracellular calcium. Neuron 3:733-743.

Caudy M, Bentley D (1986) Pioneer growth cone steering along a series of neuronal and non-neuronal cues of different affinities. $J$ Neurosci 6:1781-1795.

Chang S, Rathjen FG, Raper JA (1987) Extension of neurites on axons 
is impaired by antibodies against specific neural cell surface glycoproteins. J Cell Biol 104:355-362.

Cobbold PH, Rink TJ (1987) Fluorescence and bioluminescence measurement of cytoplasmic free calcium. Biochem J 248:313-328.

Cohan CS, Connor JA, Kater SB (1987) Electrically and chemically mediated increases in intracellular calcium in neuronal growth cones. J Neurosci 7:3588-3599.

Condic ML, Bentley D (1989) Removal of the basal lamina in vivo reveals growth cone-basal lamina adhesive interactions and axonal tension in grasshopper embryos. J Neurosci 9:2678-2686.

Cox AC, Muller B, Bonhoeffer F (1990) Axonal guidance in the chick visual system: posterior tectal membranes induce collapse of growth cones from the temporal retina. Neuron 2:31-37.

Davies JA, Cook GMW, Stern CD, Keynes RJ (1990) Isolation from chick somites of a glycoprotein fraction that causes collapse of dorsal root ganglion growth cones. Neuron 2:11-20.

Dennerll TJ, Joshi HC, Steel VL, Buxbaum RE, Heidemann SR (1988) Tension and compression in the cytoskeleton of PC-12 neurites. II: Quantitative measurements. J Cell Biol 107:665-674.

Dennerll TJ, Lamoureux P, Buxbaum RE, Heidemann SR (1989) The cytomechanics of axonal elongation and retraction. J Cell Biol 109: 3073-3083.

Downey GP, Chan CK, Trudel S, Grinstein S (1990) Actin assembly in electropermeabilized neutrophils: role of intracellular calcium. $\mathbf{J}$ Cell Biol 110:1975-1982.

Fawcett JW, Rokos J, Bakst I (1989) Oligodendrocytes repel axons and cause axonal growth cone collapse. J Cell Sci 92:93-100.

Freeman JA, Manis PB, Snipes GJ, Mayes BN, Samson PC, Wikswo JP Jr, Freeman DB (1985) Steady growth cone currents revealed by a novel circularly vibrating probe: a possible mechanism underlying neurite growth. J Neurosci Res 13:257-283.

Goldberg DJ (1988) Local role of $\mathrm{Ca}^{++}$in formation of veils in growth cones. J Neurosci 8:2596-2605.

Grynkiewicz G, Poenie M, Tsien RY (1985) A new generation of $\mathrm{Ca}^{++}$ indicators with greatly improved fluorescence properties. J Biol Chem 260:3440-3450.

Gundersen RW, Barrett JW (1980) Characterization of the turning response of dorsal root neurites toward nerve growth factor. J Cell Biol 87:546-554.

Harris AS, Morrow JS (1990) Calmodulin and calcium-dependent protease I coordinately regulate the interaction of fodrin with actin. Proc Natl Acad Sci (USA) 87:3009-3013.

Haydon PG, Cohan CS, McCobb DP, Miller HR, Kater SB (1985) Neuron-specific growth cone properties as seen in identified neurons of Helisoma. J Neurosci Res 13:135-147.

Ivins JK, Pittman RN (1989) Growth cone-growth cone interactions in cultures of rat sympathetic neurons. Dev Biol 135:147-157.

Joshi HC, Chu D, Buxbaum RE, Heidemann SR (1985) Tension and compression in the cytoskeleton of PC12 neurites. J Cell Biol 101: 697-705.

Kapfhammer JP, Raper JA (1987) Collapse of growth cone structure on contact with specific neurites in culture. J Neurosci 7:201-212.

Kater SB, Mattson MP, Cohan C, Connor J (1988) Calcium regulation of the neuronal growth cone. Trends Neurosci 11:315-321.

Kuwada JY (1986) Cell recognition by neuronal growth cones in a simple vertebrate embryo. Science 233:740-746.

Lankford KL, Letourneau PC (1989) Evidence that calcium may control neurite outgrowth by regulating the stability of actin filaments. J Cell Biol 109:1229-1243.

Letourneau PC (1978) Chemotactic response of nerve fiber elongation to nerve growth factor. Dev Biol 66:183-196.
Letourneau PC (1987) What happens when growth cones meet neurites: attraction or repulsion? Trends Neurosci 10:390-393.

Letourneau PC, Shattuck TA (1989) Distribution and possible interactions of actin-associated proteins and cell adhesion molecules of nerve growth cones. Development 105:505-519.

Lipscombe D, Madison DV, Poenie M, Reuter H, Tsien RY, Tsien RW (1988) Spatial distribution of calcium channels and cytosolic calcium transients in growth cones and cell bodies of sympathetic neurons. Proc Natl Acad Sci (USA) 85:2398-2402.

Mattson MP, Kater SB (1987) Calcium regulation of neurite elongation and growth cone motility. J Neurosci 7:4034-4043.

Mills LR, Kater SB (1989) Integration of environmental and intracellular signals: the calcium hypothesis for the control of neuronal growth cones. In: Assembly of the nervous system (Landmesser L, ed), pp 109-128. New York: Liss.

Mills LR, Kater SB (1990) Neuron-specific and state-specific differences in calcium homeostasis regulate the generation and degeneration of neuronal architecture. Neuron 4:149-163.

O'Lague PH, Huttner SL, Vandenberg CA, Morrison-Graham K, Horn R (1985) Morphological properties and membrane channels of the growth cones induced in PC1 2 cells of nerve growth factor. J Neurosci Res 13:301-321.

Patterson PH (1988) On the importance of being inhibited, or saying no to growth cones. Neuron 1:263-267.

Raper JA, Grunewald EB (1990) Temporal retinal growth cones collapse on contact with nasal retinal axons. Exp Neurol 109:70-74.

Raper JA, Kapfhammer JP (1990) The enrichment of a neuronal growth cone collapsing activity from embryonic chick brain. Neuron 4:21-29.

Rehder V, Guthrie PB, Kater SB (1989) Non-uniform distribution free calcium within a neuronal growth cone. Soc Neurosci Abstr 15: 263.8 .

Sanes JR (1989) Extracellular matrix molecules that influence neural development. Annu Rev Neurosci 12:491-516.

Schliwa M, Euteneur U, Bulinski JC, Izant JC (1981) Calcium lability of cytoplasmic microtubules and its modulation by microtubule-associated proteins. Proc Natl Acad Sci (USA) 78:1037-1041.

Schwab ME, Caroni P (1988) Oligodendrocytes and CNS myelin are nonpermissive substrates for neurite growth and fibroblast spreading in vitro. J Neurosci 8:2381-2393.

Sheetz MP, Baumrind NL, Wayne DB, Pearlman AL (1990) Concentration of membrane antigens by forward transport and trapping in neuronal growth cones. Cell 61:231-241.

Silver RA, Lamb AG, Bolsover SR (1989) Elevated cytosolic calcium in the growth cone inhibits neurite elongation in neuroblastoma cells: correlation of behavioral states with cytosolic calcium concentration. J Neurosci 9:4007-4020.

Silver RA, Lamb AG, Bolsover SR (1990) Calcium hotspots caused by L-channel clustering promote morphological changes in neuronal growth cones. Nature 343:751-754.

Thayer SA, Sturek M, Miller RJ (1988) Measurement of neuronal $\mathrm{Ca}^{2+}$ transients using simultaneous microfluorimetry and electrophysiology. Pfluegers Arch 412:216-223.

Tolkovsky AM, Walker AE, Murrell RD, Suidan HS (1990) $\mathrm{Ca}^{2+}$ transients are not required as signals for long term neurite outgrowth from cultured sympathetic neurons. J Cell Biol 110:1295-1306.

Yamamoto H, Fukunaga K, Tanaka E, Miyamoto E (1983) $\mathrm{Ca}^{++}$and calmodulin-dependent phosphorylation of microtubule-associated protein 2 and tau factor, and inhibition of microtubule assembly. $J$ Neurochem 41:1119-1125. 